\title{
Saber Estatístico: uma forma de olhar para as produções acadêmicas do PROFMAT
}

\section{Statistical Knowledge: a way of perceiving the academic productions of PROFMAT}

\author{
Susana Beatrís Oliveira Szewczyk ${ }^{*}$ \\ ORCID iD 0000-0003-2339-0286 \\ Rochele de Quadros Loguercio** \\ ORCID iD 0000-0002-8464-4801
}

\begin{abstract}
Resumo
Este artigo destaca uma análise dos Trabalhos de Conclusão de Curso do Mestrado Profissional em Matemática em Rede Nacional, especificamente, os que tratam dos usos do saber estatístico, a partir dos conceitos de discurso e governamentalidade de Michel Foucault. Para tal, na primeira seção do artigo, visibilizamos a inclusão dos números como prática discursiva na sociedade contemporânea. Na segunda, apresentamos o entendimento do saber estatístico como uma tecnologia de governamento. Logo após, na terceira seção, tratamos o discurso como prática. $\mathrm{Na}$ quarta, a partir dos conceitos adotados, analisamos as produções acadêmicas dos professores/alunos do Mestrado Profissional. Nessas produções percebemos que os usos do saber estatístico operam ora produzindo, ora reproduzindo saberes que posicionam os sujeitos quando da sua relação com números, índices, taxas, gráficos e tabelas.
\end{abstract}

Palavras-chave: Tecnologia de Governamento. Saber Estatístico. Discurso. Prática.

\begin{abstract}
This paper highlights an analysis in the Conclusion Papers of the Professional Master's Degree Course in Mathematics in National Network, specifically, those that deal with the uses of statistical data, from the concepts of discourse and governmentality of Michel Foucault. With that objective, in the first section of the present paper, we included the numbers as a discursive practice in contemporary society. In the second section, the understanding of statistical knowledge is presented as a governance technology of governance. In the third section, the discourse is dealt as practice. In the fourth section, from the adopted concepts, we analyze the academic productions of the professors/ students of the professional master's degree. In these productions, we noticed that the use of statistical knowledge operate either by producing, or by reproducing the knowledge that positions the subjects in their relationship with numbers, indexes, rates, graphs and tables.
\end{abstract}

Keywords: Governance Technology. Statistical Knowledge. Discourse. Practice.

\footnotetext{
* Doutora em Educação em Ciências pela Universdade Federal do Rio Grande do Sul (UFRGS). Docente no Instituto Federal de Educação, Ciência e Tecnologia do Rio Grande do Sul (IFRS), Porto Alegre, Rio Grande do Sul, Brasil. Endereço para correspondência: Rua Alberto Hoffmann, 285, Bairro Restinga, Porto Alegre, Rio Grande do Sul, Brasil, CEP: 91791-508. E-mail: susana.szewczyk@ restinga.ifrs.edu.br.

** Pós-Doutora em Filosofia pela Universidad Complutense de Madrid (UCM), Espanha e Doutora em Educação em Ciências pela Universdade Federal do Rio Grande do Sul (UFRGS). Docente na Universdade Federal do Rio Grande do Sul (UFRGS), Porto Alegre, Rio Grande do Sul, Brasil. Endereço para correspondência: Rua Ramiro Barcelos, 2600, Departamento de Bioquímica, Prédio Anexo, Bairro Rio Branco, Porto Alegre, Rio Grande do Sul, Brasil, CEP: 90035-003. E-mail: rochelel@gmail.com
} 


\section{Os números na sociedade contemporânea}

\section{[...] Números, números, números, O que é, o que são, O que dizem sobre você? [...]}

Papas da Língua (Números, números, números. O que é, o que são. O que dizem sobre você. Números, números ..., 1993)

Começamos a escrita do artigo com um trecho da música Essa não é a sua vida, lembrando o quanto os números estão incluídos nos diversos discursos de uma sociedade. Como escreve Senra, são os números “[...] (e as estatísticas) [que] povoam (não raro, assombram) nossos cotidianos, como força de argumentação" (SENRA, 2005, p. 24, grifos do autor).

A centralidade dos números na sociedade moderna - e as diferentes maneiras pelas quais os índices e as taxas adquirem relevância - tem sido estudada, nas últimas décadas, em perspectivas pós-críticas que, dentre tantos achados, evidenciam sua potencialidade para determinar nossas condutas.

Da música à academia, passando por diversos matizes da vida cotidiana, os números têm ocupado um lugar de destaque na conformação do nosso corpo (índices de massa corporal "normais", por exemplo), na escolha de nossa vida laboral (qual profissão remunera melhor, por exemplo), na nossa vida acadêmica (quantos artigos publicados por ano), na nossa escolha de telefones, planos, projetos e, sobretudo, nos nossos critérios de verdade; esse último um dos maiores investimentos da vida moderna.

No campo educacional, as estatísticas ${ }^{1}$ produzidas pelo Instituto Nacional de Estudos e Pesquisas Educacionais Anísio Teixeira (Inep) ${ }^{2}$ expressam, na forma de números, índices, taxas, tabelas e gráficos, informações referentes à formação dos professores da Educação Básica, entre outras, que não apenas mapeiam a "situação" do Estado, mas que:

[...]subsidiam a formulação e implementação de políticas públicas para a área educacional a partir de parâmetros de qualidade e/ou equidade, bem como a produção de informações claras e confiáveis aos gestores, pesquisadores, educadores e público em geral (CURI, 2016) ${ }^{3}$.

\footnotetext{
${ }^{1}$ Utilizamos a palavra 'estatísticas' quando nos referimos aos dados provenientes de pesquisas. Já a palavra 'Estatística' é utilizada para nos referirmos à maneira pela qual um conjunto de dados é coletado, analisado e interpretado, ou seja, a Estatística Descritiva.

${ }^{2}$ Disponível em: <http://portal.inep.gov.br/sinopses-estatisticas>. Acesso em: 29 out. 2016.

3 Entrevista dada por Luis Roberto Curi, presidente do Inep, a Assessoria de Comunicação Social do Instituto. Disponível em: <http://portal.inep.gov.br/web/guest/conheca-o-inep>. Acesso em: 29 out. 2016.
} 
As perguntas que nos ocorrem, necessariamente, são: Foi sempre assim? É possível entender o Estado e suas necessidades de outra forma? Quais os efeitos, ou quais as condições de existência de uma Matemática do Estado, de uma Estatística?

Nesse sentido, algumas obras de Michel Foucault possibilitam entender uma mudança bastante marcada na relação entre Estado e sujeitos de direito desse Estado; uma delas é a quebra entre sujeito e espécie, uma mudança do olhar do Estado para a população.

Um tratamento prioritário passa a ser dado a partir da emergência do fenômeno "população", principalmente através da economia e da Estatística, esta uma forma "estatal" de controle que se dirige ao homem enquanto espécie, nos seus processos de reprodução, natalidade, mortalidade, difusão de doenças, regularidade de acidentes, grau de instrução ou analfabetismo, etc. Toda uma série de dispositivos é criada no sentido de garantir certos padrões dessa reprodução e certo direcionamento na circulação dessa população.

A amplitude e a dispersão do controle na forma de população já não são mais territoriais, pois estão bem mais postas no "meio", o que implica entender que o território se amplia para as redes. Em consonância com tais entendimentos, não é estranho que as orientações das Organizações Internacionais para formação docente despontem nas políticas públicas brasileiras e, assim, coloquem em circulação outros discursos, entre eles: o discurso sobre qualidade na Educação Básica, as políticas de licenciaturas e/ou a promoção da pós-graduação stricto sensu e lato sensu. Especificamente, nessa confluência entre as políticas de governo e os dispositivos de segurança, a educação pode ser entendida como uma estratégia de controle.

Nesta pesquisa, tomamos o Mestrado Profissional em Matemática em Rede Nacional (PROFMAT) como efeitos e ferramentas de uma rede de políticas na qual a Estatística operou/opera/operará enquanto tecnologia de governo. O material de análise dessa estratégia de governo, centrada na população de docentes de Matemática, é constituído por 19 Trabalhos de Conclusão de Curso (TCC), nos quais se buscou entender como estão evidenciadas as orientações de uma determinada prática discursiva.

O PROFMAT foi o primeiro Mestrado Profissional a ser instituído e nasceu junto a uma prática discursiva numérica de qualificar, até 2024, 50\% dos docentes da Educação Básica como uma das possibilidades de garantir "[...]a todos(as) os(as) profissionais da Educação Básica formação continuada em sua área de atuação"(PROFMAT, 2011) ${ }^{4}$. Ele é destinado aos professores da rede pública de ensino em efetivo exercício e foi implantado a partir de uma série de cálculos e de saberes que têm uma intencionalidade política: alterar, de forma positiva,

\footnotetext{
${ }^{4}$ Disponível em: <http://www.profmat-sbm.org.br/organizacao/apresentacao>. Acesso em: 16 jan. 2015.
} 
os índices das avaliações educacionais no país.

Portanto, nosso objetivo é analisar as produções discursivas que emergem no cenário dessa qualificação stricto sensu em relação aos usos do saber estatístico e que estão materializados nos TCC.

\section{O saber estatístico como tecnologia de governamento}

A palavra Estatística - Statistik - foi criada, em 1749, pelo professor Gottfried Achenwall (1719-1772). Ao fazê-lo, o autor a definiu como sendo a descrição, em um sentido amplo, da constituição de fatos notáveis a respeito do Estado: seu poder, suas fraquezas.

Nesse pensamento, podemos argumentar que a "criação" do vocábulo Estatística está para além de uma constituição de fatos notáveis, passando a se constituir como uma ferramenta na definição do próprio Estado e seu governo. No entanto, isso só pode ser compreendido se percebermos que, em um primeiro movimento, a Estatística não se destinava à análise e à interpretação de dados quantitativos, como é feito na atualidade.

Há indícios de que em 3000 a.C., seu uso se destinava à criação de listas que continham os nomes dos proprietários das terras e sobre o que nelas havia. Isso era realizado com o objetivo específico de conhecer para taxar. Além disso, essas listas tinham um outro objetivo importante: elas tornavam conhecidos os homens aptos a guerrear. Assim, o primeiro uso da Estatística tinha uma função interna de controle, mas que, somente mais tarde, passou a ser uma ferramenta ampla de controle governamental.

De acordo com Senra (2005), apesar da palavra Estatística ser cunhada no ambiente acadêmico, isso fez com que ela tivesse um caráter especial, com rasgos de ciência. Porém, seu significado vai além. A própria ciência, ao se apoiar na Matemática, fortalece a rede de saberes que coloca a matematização do Estado como ciência.

Porém, como Senra destaca, essa não é a única vertente associada à Estatística. Ela também é concebida como a ciência utilizada pelos aritméticos políticos, homens que "[...] praticaram a elaboração de estatísticas utilizando os registros existentes" (SENRA, 2005, p. 78).

Nas palavras de Michel Foucault (2008, p. 365, grifo do autor) a Estatística é:

o conhecimento do Estado, o conhecimento das forças e dos recursos que caracterizam um Estado num momento dado. Por exemplo: conhecimento da população, medida da sua quantidade, medida da sua mortalidade, da sua natalidade, estimativa das diferentes categorias de indivíduos num Estado e da sua riqueza, estimativa das riquezas virtuais de que um estado dispõe: minas, florestas, estimativa das riquezas produzidas, estimativa das riquezas que circulam, estimativa da balança comercial, 
medida dos efeitos das taxas e dos impostos - são todos esses dados e muitos outros que vão constituir agora o conteúdo essencial do saber do soberano. Não mais, portanto, corpus de leis ou habilidade em aplicá-las quando necessário, mas conjunto de conhecimentos técnicos que caracterizam a realidade do próprio Estado.

Isso nos possibilita pensar em como o saber estatístico se torna a ciência utilizada pelos governos para administrar, numa escala macro, a população das cidades, dos Estados e do país e, numa escala micro, os modos de ser, de pensar e de agir dos indivíduos. Em outras palavras, o saber estatístico é um saber que interessa ao governo, pois é através dele que o Estado regula e conduz a população (entre essa, a população docente) e as suas instituições (entre essas, as escolas e as universidades).

Como explica Foucault (2004), o saber é o conjunto de elementos necessários e indispensáveis à constituição de práticas sociais e sua produção é condição para o exercício de poder. Assim, mesmo ao ser tomado como um saber científico, o saber estatístico não escapa a essa definição.

Não por acaso, tratamos o saber estatístico como uma tecnologia de governamento ${ }^{5}$. Ao fazê-lo, estamos considerando-o como uma tecnologia que opera na condução dos indivíduos para o controle e para a administração de uma população.

É apoiado nas estatísticas que o governo instituiu as políticas públicas voltadas à formação e à qualificação docente no país, conforme preconizado pelas Organizações Internacionais. Assim, a formação e a qualificação docente podem ser vistas como efeitos de uma ação do governo, que busca na condução do professor, produzir efeitos na docência contemporânea pela mínima aplicação de poder. Especificamente neste texto, tratamos de uma dessas políticas de governo: o PROFMAT, mestrado que tem uma estrutura diferente dos demais mestrados profissionais existentes no Brasil. O PROFMAT foi instituído com o objetivo de, numa microescala, qualificar os docentes da Educação Básica em exercício nas salas de aula e, numa macroescala, alterar os índices das avaliações educacionais realizadas no país. Por isso, tratamos o saber estatístico como um saber essencial às práticas de governo.

Na perspectiva foucaultiana, à medida que se constroem saberes sobre uma população, objetiva-se conhecer a todos (e a cada um) por meio de estratégias que se destinam a garantir a sua seguridade. O saber estatístico, enquanto tecnologia de governamento, faz parte da racionalidade política que encontra na qualificação docente, por exemplo, um dos mecanismos produtivos para sua efetivação.

A qualificação do professor, por sua vez, é operacionalizada como formação do docente

\footnotetext{
5 Veiga-Neto (2002) propõe o uso da palavra governamento para tratar das ações de direcionamento das condutas dos indivíduos, enquanto que o termo governo é utilizado para se referir à instância governamental.
} 
para aceitar a racionalidade governamental como sua própria, garantindo a matematização naturalizada como verdade individual e coletiva, mesmo que não perceba todo um dispositivo de poder e de saber que a perpassam. A apropriação pelos docentes, tanto quanto pelos seus alunos e pares nas escolas, minimiza as dificuldades de se implantar politicas meritocráticas, por exemplo, bem como aceitar conceitos econômicos como perdas e danos. Nesse caminho, a Matemática, e em particular a Estatística, ao assumir-se como pressuposto de objetividade e de neutralidade característicos da ciência moderna, parece não estar associada às demandas de uma racionalidade econômica mercadológica; assim constitui-se sub-repticiamente sem aceder a discursos de resistência em outras formas mais presentes.

\section{0 discurso como prática}

É a partir dos estudos de Foucault que compreendemos que os documentos acabam se transformando em monumentos. São os monumentos que criam condições para confrontar as coisas ditas e as coisas feitas, fatos surpreendentes, questionados naquilo que, até então, tinham de óbvios e mostrados a partir de saliências, reticências, descontinuidades, acasos e casos históricos. Nesse pensamento, todo e qualquer documento será tratado na condição de objeto no interior de um conjunto de práticas (FISCHER, 2003, p. 378).

$\mathrm{Na}$ perspectiva foucaultiana (FOUCALT, 2012, p. 60), os discursos não devem ser tratados como um conjunto de signos, mas como práticas que formam sistematicamente os objetos de que falam. Podemos dizer, então, que o discurso "não é uma entidade que paira sobre os fatos e os objetos do mundo, aguardando o momento de sobre eles repousar e fornecer-lhes o sentido". São os discursos que, ao produzirem objetos de conhecimento, também produzem "[...]domínios de saber sobre esses objetos, e as subjetividades que lhe são contemporâneas" (TEIXEIRA, 2008, p. 601).

Portanto, ao adotarmos o conceito de discurso de Foucault, estamos considerando um tipo de análise que não trata do problema do sujeito falante "[...]mas examina as diferentes maneiras pelas quais o discurso desempenha um papel no interior de um sistema estratégico em que o poder está implicado e para qual o poder funciona" (FOUCAULT, 2006, p. 253). Em sua primeira abordagem, o discurso já era tomado como prática, mas apenas depois dos estudos com a ênfase no poder e no governo que Foucault formulou e se apropriou do conceito de prática como o imbricamento dos dispositivos epistêmicos e de poder que, mais do que governar aos outros, governa a nós mesmos. 
A perspectiva de poder em Foucault é muito importante e diferente das perspectivas às quais estamos acostumados, como as advindas da teoria crítica ou das teorias positivistas, o que nos mobiliza a traçar mais algumas características das teorias foucaultianas sobre o poder.

Foucault, no texto Segurança, Território e População, começa a produzir uma analítica do poder que se diferencia das análises anteriores, como, por exemplo, a ideia de arenas de luta ou a metáfora da guerra presente no seu livro Vigiar e Punir. Para o autor, "o poder não é nem fonte e nem origem do discurso. O poder é alguma coisa que opera através do discurso, já que o próprio discurso é um elemento em um dispositivo estratégico de relações de poder" (FOUCAULT, 2006, p. 253).

Por isso, neste artigo, tomamos como objeto de análise os documentos enquanto monumentos em sua perspectiva de práticas discursivas no campo da Estatística. Ao tratarmos o saber estatístico como uma prática, podemos perceber uma série de estratégias de poder atuando através dele e de sua capacidade de conduzir as condutas.

Como destaca Foucault (2012), por prática não se entende a atividade de um sujeito, mas a existência objetiva e material de certas regras às quais o sujeito obedece ao participar do discurso, ocupando determinadas posições.

É na compreensão de que as regularidades discursivas "são pautadas por regras, as mesmas que dão existência, coexistência, manutenção, modificação, ou mesmo fazem desaparecer as repartições discursivas em determinadas instâncias” (BELLO, 2010, p. 563) que Foucault trata o discurso como prática. Dito de outro modo: é pelo caráter regrado dos discursos que Foucault os considera como práticas.

Assim, pensamos nos TCC que sitiam suas temáticas no campo da Estatística como documentos monumentalizados que, ao pertencerem a determinados conjuntos discursivos e que, por sua vez, estão definidos por regras, são efeitos de uma rede de significados em que os sujeitos profmatores ${ }^{6}$ estão inseridos. A partir disso, entendemos as práticas que emergem no cenário da qualificação docente, em nível de pós-graduação stricto sensu, como sendo efeitos de um processo histórico que modifica discursos.

Portanto, é a partir desse entendimento que os discursos são analisados neste artigo, a saber, como práticas, buscando não aquilo que queria ser dito nesses documentos, ou que deveria ter sido dito, mas aquilo que está dito.

\footnotetext{
${ }^{6}$ Professores/alunos do PROFMAT.
} 


\section{Os ditos}

Ao tomarmos o saber estatístico como objeto de nosso estudo sobre a qualificação stricto sensu em Matemática, focamos nosso domínio nas escrituras produzidas nos TCC do PROFMAT. O material em análise é composto por $19 \mathrm{TCC}^{7}$, com formatos ${ }^{8}$ diversos e disponibilizados no sítio eletrônico ${ }^{9}$ deste Mestrado Profissional.

Em decorrência da diversidade de textos e de temáticas, estabelecemos como critério inicial de análise a busca da relação entre Estatística e a sociedade contemporânea, pois partimos de uma análise pós-estruturalista, cujo conceito de governamentalidade evidencia a relação entre governo e sociedade, composto junto e pela Estatística.

Um primeiro momento de observação e análise dos TCC parece indicar que um dos mais efetivos modos de entendimento da Estatística está vinculado a duas expressões que surgem com determinada recorrência: "tomada de decisão" e "formas de ler o mundo".

Importa ressaltar que essas expressões aparecem quando os profmatores tomam como aporte teórico os documentos oficiais da Educação, os Parâmetros Curriculares Nacionais (PCN) e os Parâmetros Curriculares Nacionais do Ensino Médio (PCNEM), para justificar, além da escolha do tema, cada um dos procedimentos metodológicos adotados em suas pesquisas.

O conjunto discursivo que compõe os inúmeros TCC disponibilizados no sítio eletrônico do PROFMAT pode, aqui, ser tomado como um único texto, pois o entendimento e a aplicabilidade da Estatística, ainda que tenham nuances diferentes, têm, na sua constituição de saber, uma tendência em comum que é acreditar na legislação e buscar a aplicação da Estatística

\footnotetext{
7 Conforme Regimento (Versão 2012) em seu Artigo 28 - O Trabalho de Conclusão de Curso deve versar sobre temas específicos pertinentes ao currículo de Matemática do Ensino Básico e que tenham impacto na prática didática em sala de aula. Disponivel em:<http://www.profmat-sbm.org.br/funcionamento/regimento/>. Acesso em: 22 nov. 2015.

8 Conforme dispõe a Portaria Normativa $N^{\circ}$ 17, de 28 de dezembro de 2009, da Fundação Coordenação de Aperfeiçoamento de Pessoal de Nível Superior (CAPES), em seu Artigo $7^{\circ}$ : A proposta de Mestrado Profissional deverá, necessária e obrigatoriamente; Inciso VIII - prever a exigência de apresentação de trabalho de conclusão final do curso; $\S 3^{\circ} \mathrm{O}$ trabalho de conclusão final do curso poderá ser apresentado em diferentes formatos, tais como dissertação; revisão sistemática e aprofundada da literatura; artigo; patente; registros de propriedade intelectual; projetos técnicos; publicações tecnológicas; desenvolvimento de aplicativos, de materiais didáticos e instrucionais e de produtos processos e técnicas; produção de programas de mídia; editorial; composições; concertos; relatórios finais de pesquisa; softwares; estudos de caso; relatório técnico com regras de sigilo; manual de operação técnica; protocolo experimental ou de aplicação em serviços; proposta de intervenção em procedimentos clínicos ou de serviço pertinente; projeto de aplicação ou adequação tecnológica; protótipos para desenvolvimento ou produção de instrumentos, equipamentos e kits; projetos de inovação tecnológica; produção artística sem prejuízo de outros formatos, de acordo com a natureza da área e a finalidade do curso, desde que previamente propostos e aprovados pela CAPES.

9 Disponível em: <http://www.profmat-sbm.org.br/dissertacoes?pag=79>. Acesso em: 13 set. 2016.
} 
na estrutura de sala de aula, tal qual é pensada pelos proponentes desse Mestrado Profissional. Como destaca um dos profmatores:

A Estatística cria a possibilidade de estratégias a serem adotadas em um empreendimento, na escolha de técnicas de verificação e avaliação da quantidade e da qualidade, além de lucros e prejuízos (LEITÃO, 2013, p. 21).

No entanto, essa frase tem sua relação imediata e bastante direta com um posicionamento neoliberal que se compromete com uma forma de hierarquizar os dados estatísticos numa economia necessária à manutenção de um determinado mercado do saber.

Quando somamos essa frase a uma forma de pensamento nascida e dispersa na década de 80 sobre a importância do cotidiano no currículo da Escola Básica, podemos dizer que há uma busca da reprodução de uma "verdade" estatística que, ao conduzir populações, serve para conduzir condutas.

Ou seja, podemos identificar nos textos que a Estatística serve, na microescala, nas diferentes salas de aulas, para produzir ou criar uma conduta em que a decisão sobre as escolhas não mais está vinculada a valores sociais ou éticos, ou mesmo históricos e herdados, mas à potência do número que, ao não individualizar, impede a percepção dos diferentes e bloqueia a possibilidade de autonomia que, em outros discursos educacionais, tanto se advoga como base da escola pública.

Percebemos que os textos analisados pontuam os usos da Estatística, na atualidade, destacando a necessidade do "desenvolvimento das capacidades de comunicação, de resolver problemas, de tomar decisões, de fazer inferências, de criar, de aperfeiçoar conhecimentos e valores, de trabalhar cooperativamente" (BRASIL, 1997, p. 44), tal como aparece na legislação.

Se pensarmos no saber estatístico como um possível "agente de transformação da vida", podemos compreender os seguintes excertos:

Aplicar os conteúdos na sua própria vivência e que os mesmos sirvam de ferramenta nas suas ações de trabalho, consumo e vida de modo geral (NASCIMENTO, 2014, p. 17).

O currículo escolar precisa atender as necessidades cotidianas do cidadão e utilizar o conhecimento aprendido na escola em situações reais da vida diária (BATISTA, 2013, p. 25).

Realizar pesquisas de campo e, consequentemente, durante as aulas, trabalhar com dados estatísticos reais, e discutir, não só com o professor, mas também com os colegas, assuntos pertinentes ao seu dia a dia (NOVANTA, 2013, p. 52).

O objetivo principal desta proposta é o de estimular a criatividade do educando e fazêlos realizar uma conexão do cotidiano com os conteúdos aprendidos em sala de aula, consolidando e aprofundando os conhecimentos estatísticos, introduzindo o uso de softwares livres para a análise dos dados, com base nos conhecimentos estatísticos adquiridos ao longo das observações do dia a dia e prepará-lo para a vida profissional, tornando-o um sujeito capaz de tomar as suas próprias decisões (COSTA, 2013, p. 2). 
Cada uma dessas frases traz em seu escopo uma aceitação da legislação e não produzem uma crítica à essa, o que nos permite compreender que, durante o curso, algumas perspectivas que vão de encontro à legislação não são consideradas, como as de Lopes (2003, p. 56), que faz uma crítica à forma de entender a Estatística. Conforme essa autora, a Estatística é uma ciência que "não se restringe a um conjunto de técnicas. Ela contribui com conhecimentos que permitem lidar com a incerteza e a variabilidade dos dados [...] possibilitando tomadas de decisão com maior argumento". Outra autora pontua que "sua importância está, portanto, menos na provisão de uma descrição exata e completa do real e sim na sua capacidade de ordenar e sintetizar informações conferindo inteligibilidade ao mundo" (GIL, 2007, p. 23).

A incerteza parece não pertencer aos TCC e, portanto, há uma compreensão direcionada e única da Estatística como uma definição do real e não como uma organização do real num objetivo específico.

\section{Conforme destacam Castro e Cazorla (2007):}

os números passam a ideia de cientificidade, de isenção, de neutralidade. Quando os discursos, as propagandas, as manchetes e notícias veiculadas pela mídia, utilizam informações estatísticas (números, tabelas ou gráficos), essas ganham credibilidade e são difíceis de serem contestadas pelo cidadão comum, que chega até questionar a veracidade dessas informações, mas não está instrumentalizado para arguir e contra argumentar (CASTRO; CAZORLA, 2007, p. 1-2).

Essa marcação de ciência, e de científico, acompanha a constituição de professores e de cientistas há muito tempo, sendo que os profmatores, além de não questionarem a Matemática e sua Estatística, são incapazes de aceitar a subjetividade da ciência e os limites dos números na escala social, tratando de seu objeto de estudo como uma ferramenta capaz de entender e de agir no mundo, da mesma forma que no mundo in vitro. Assim, a sociedade se comporta, segundo a Estatística, como uma amostra em um laboratório, capaz de dizer a verdade sobre o fenômeno e, ademais, produzir formas de agir sobre ele.

Nas leituras realizadas, podemos perceber que a expressão "tomada de decisão" surge sempre em relação à importância da Estatística na atualidade. Em relação a essa expressão, os profmatores pontuam:

O ensino da Estatística pode servir como ferramenta que colabora na tomada de decisão por parte dos alunos, levando-os a se decidirem com maior segurança, pelo que é plausível no cenário contemporâneo (MORETTI, 2013, p. 19).

$\mathrm{Na}$ atualidade, a Estatística não se reduz apenas a levantamentos demográficos, pois extrapola a simples coleta de dados, permitindo através da análise e do cálculo de probabilidades que sejam realizadas inferências a partir dos dados coletados. Foi, nesse contexto, que os conhecimentos de Estatística se tornaram extremamente importantes, pois através deles temos a possibilidade de analisar as diversas modificações do mundo atual e principalmente ponderar diversas tomadas de decisões de forma mais precisa (FORTES, 2014, p. 13). 
Possibilita comparar resultados para tomadas de decisões, [e] deve ser uma constante para todos os nossos educandos (BATISTA, 2013, p. 73).

Nas produções acadêmicas, os ditos em relação ao uso do saber estatístico como "formas de ler o mundo" aparecem associados com a possibilidade de o indivíduo se inserir na sociedade e, assim, exercer a cidadania. Ou seja, o saber estatístico é entendido como um elemento constituinte do exercício da cidadania utilizando de diferentes estratégias que operam com o intuito de incluir os indivíduos, na contemporaneidade.

Nas palavras dos profmatores:

É necessário que as pessoas estejam cada vez mais preparadas para entender e refletir a respeito das imagens e dados que lhes são mostrados, e que sejam capazes de interpretar as inúmeras informações que são apresentadas a respeito dos mais variados temas. [Para tal, faz-se necessário] inserir os conhecimentos relacionados ao tratamento da informação e ao raciocínio estatístico entre as competências básicas para o exercício da cidadania (BODART, 2013, p. 1).

O aluno precisa saber como produzir e comunicar informações estatísticas, pois desta forma ele poderá exercer melhor sua cidadania, aprimorar sua vida acadêmica e profissional (SANTOS, 2013, p. 5).

Aqui, podemos ver o saber estatístico operando como uma forma de inclusão à medida que aproxima os sujeitos de uma sociedade para constituí-los como uma população "que tem suas regularidades, seus riscos próprios, suas ameaças, mas que, estando perto e sendo conhecida, pode ser controlada e governada" (LOCKMANN, 2010, p. 193).

Conforme destaca um dos profmatores, a interpretação das informações estatísticas, a partir de dados, tabelas e gráficos, é uma constante na sociedade atual. Nas palavras dele:

Interpretar é fazer bom uso de todas as informações que nos cercam e que constantemente são coletadas e apresentadas em formas de tabelas, gráficos, pictogramas (OLIVEIRA, 2014, p. 5).

Nesse pensamento, Wallman (1993) evidencia a necessidade que a sociedade atual tem em formar sujeitos alunos capazes de interpretar informações estatísticas. Para esse autor, interpretar informações de cunho estatístico possibilita aos indivíduos entender e avaliar os gráficos e tabelas que adentram o seu cotidiano.

Porém, como alerta Lopes, "não basta ao cidadão entender as porcentagens expostas em índices estatísticos, como o crescimento populacional, taxas de inflação, desemprego". "É preciso analisar/relacionar criticamente os dados apresentados, questionando/ponderando até mesmo sua veracidade" (LOPES, 2008, p. 60).

Três excertos visibilizam as discussões que tratam do "saber ler e interpretar" informações estatísticas:

Atualmente as pessoas precisam muito mais do que saber ler e escrever. A nossa sociedade necessita de pessoas que sejam capazes de analisar uma determinada 
informação e, posteriormente, tomar decisões com base nessa análise (GOMES, 2013, p. 6).

A Estatística, na tomada de decisão, tem um papel fundamental de facilitadora da leitura e conhecimento desta sociedade (OLIVEIRA, 2014, p. 1).

Vivemos num mundo que bombardeia informações, [onde] a cada dia, os jornais e [as] revistas diminuem suas falas e mostram, de forma resumida e clara, suas notícias através da Estatística. Logo, precisamos saber selecionar, compreender, interpretar e [formar] opinião para sermos cidadãos participativos e atuantes na sociedade ao qual estamos inseridos (LEITÃO, 2013, p. 35).

Nesses excertos, percebemos que os profmatores atribuem à Estatística uma forma de compreensão da vida dos indivíduos. Alguns profmatores buscam esse entendimento em outros referenciais. Ele aparece nomeado por "letramento estatístico".

Um texto legal destaca o "letramento estatístico" como sendo a capacidade do estudante de "ir além dos conhecimentos escolares, analisar, raciocinar e refletir ativamente sobre seus conhecimentos e experiências, e enfoca competências que serão relevantes para a vida" (INEP, 2012, p. 19).

Tal como percebemos nos TCC a "influência" da Legislação Federal (PCN e PCNEM) na construção dos trabalhos e nos entendimentos da Estatística no cotidiano, também identificamos, aqui, os textos legais atuando sobre uma ideia de leitura desse cotidiano. Isso nos possibilita entender o "letramento estatístico" como uma categoria que classifica os indivíduos. Ao classificá-los, isso possibilita que esses sujeitos sejam esquadrinhados tornandoos conhecidos e, portanto, governáveis. Porém, cabe destacar que não basta o governo produzir estatísticas. Por isso, se advoga sua inserção na Educação Básica, pois quanto mais cedo os indivíduos souberem lidar com essas informações, mais chances têm de gerenciar os riscos a que possam estar submetidos, o que acarreta menores investimentos por parte do Estado em intervenções para potencializar um modo de vida da população.

Afinal de contas, como diz Foucault, "somos julgados, condenados, classificados, obrigados a tarefas, destinados a uma certa maneira de viver ou a uma certa maneira de morrer, em função de discursos verdadeiros, que trazem consigo efeitos específicos de poder" (FOUCAULT, 2010, p. 22).

Cabe questionar, como Lopes (1998) faz em outro excerto, a veracidade da Estatística no mundo, a Estatística que produz mundos, um mundo a ser lido estatisticamente. Isto é, os profmatores passam a argumentar diante da sua escolha e da sua ciência (Estatística), tomando o entendimento do governo que a usa como forma de controle de uma população, já que estamos entendendo esse controle como uma tecnologia de governamento necessária a uma política de gestão neoliberal e que, segundo Foucault, é uma forma de pensar a racionalidade política que 
utiliza diferentes estratégias de poder para o governamento dos indivíduos.

Conforme escreve o autor,

$\mathrm{O}$ encontro entre as maneiras pelas quais os indivíduos são dirigidos por outros e os modos como conduzem a si mesmos, é o que se pode chamar, creio, de governo. Governar pessoas, no sentido geral da palavra não é um modo de forçá-las a fazer o que o governo quer; é sempre um ponto de equilíbrio, com complementaridades e conflitos entre técnicas que garantem a coerção e os processos pelos quais o sujeito é construído e modificado por ele mesmo (FOUCAULT, 2011a, p. 155).

No entanto, em nenhum dos textos analisados, parece se encontrar uma resistência à "verdade" estatística, ou mesmo à realidade que essa Estatística constrói. Todo um investimento de produção de mestres profissionais fica submisso ao entendimento científico e neutro de uma sociedade ainda positivista no que concerne ao conhecimento científico.

Destacamos, também, que algumas das produções apontam para o uso do saber estatístico como facilitador no intercâmbio entre as demais ciências. Nessa direção, alguns excertos pontuam:

As pessoas precisam estar preparadas para refletir a respeito das informações, para analisar, interpretar e tratar diferentes dados oriundos de diferentes modalidades de publicações, pesquisas e estudos (BODART, 2013, p. 1).

A Estatística está presente em nosso cotidiano de forma constante e fortemente inserida no currículo de matemática da educação básica. Apresenta-se como uma ciência interdisciplinar, mostrando-se uma valiosa e poderosa ferramenta na tomada de decisões seja em empresas, comércio em geral, no próprio campo de estudos e pesquisas ou na própria divulgação dos fatos pelos jornais, revistas, televisão, internet (NASCIMENTO, 2014, p. 16).

[A Estatística] está presente em várias profissões e situações como: na administração, nas pesquisas de mercado, nas ciências humanas, nas ciências biométricas (agronomia, psicologia, médicas), no mercado financeiro, no planejamento, no orçamento, nas previsões de venda. Isso mostra o quanto ela é interdisciplinar, pois proporciona uma grande esperança de renovação e mudança. Ela propicia as condições necessárias para coexistência de um diálogo entre as disciplinas. [A Estatística] tem a finalidade de estabelecer uma relação que leve o aluno a compreender, processar, pensar, criticar e incorporar os diferentes conteúdos e as ligações entre as disciplinas, permitindo-lhe uma construção coerente e a lógica dos conhecimentos adquiridos nas diferentes áreas (LEITÃO, 2013, p. 16).

Cabe destacar que a interdisciplinaridade não tem, segundo os PCN, "a pretensão de criar novas disciplinas ou saberes, mas de utilizar os conhecimentos de várias disciplinas para resolver um problema" (BRASIL, 2006, p. 21), o que manteria a Estatística como uma ciência potente e única, cujos sabedores são muito importantes para as demais ciências. Há, nesse sentido, uma extrapolação dos domínios das estatísticas e, ao mesmo tempo, uma manutenção de sua identidade.

Ainda, conforme esse documento:

A articulação da Matemática ensinada no ensino médio com temas atuais da ciência e da tecnologia é possível e necessária. Deve-se observar que as articulações com as práticas sociais não são as únicas maneiras de se favorecer a atribuição de significados 
a conceitos e a procedimentos matemáticos, pois isso igualmente é possível, em muitos casos, com o estabelecimento de suas conexões com outros conceitos e procedimentos matemáticos importantes (BRASIL, 2006, p. 95).

Sob esse ponto de vista, Júnior (2007, p. 35) pontua que seria interessante que as práticas e os conteúdos ministrados na sala de aula "estejam em sintonia com as novas exigências do mundo em que vivemos, para que a educação não seja algo distante da vida dos alunos, mas, ao contrário, seja parte integrante de suas experiências para uma existência melhor”. Tal entendimento aparece no excerto:

O ensino de Estatística também abre novas possibilidades educativas, como a de levar o aluno a perceber a importância do uso dos meios tecnológicos disponíveis, na sociedade contemporânea (NORONHA, 2014, p. 18).

Segundo a legislação, as sociedades atuais são sociedades globalizadas e que necessitam de indivíduos capazes de "acompanhar o desenvolvimento tecnológico contemporâneo, tomando contato com os avanços das novas tecnologias nas diferentes áreas do conhecimento para se posicionar frente às questões de nossa atualidade” (BRASIL, 1997, p. 26). Por isso, de acordo com tal documento, faz-se necessário que os indivíduos sejam capazes de "utilizar diferentes tecnologias e linguagens (que vão além da comunicação oral e escrita), instalando novos ritmos de produção, de assimilação rápida de informações, resolvendo e propondo problemas em equipe" (id., p. 6).

Nos excertos analisados, percebemos que as expressões "tomada de decisão" e "formas de ler o mundo" que emergiram nas produções, acabam por confluir para o uso da Estatística como uma possibilidade de inserção dos indivíduos no mundo contemporâneo.

Foi possível perceber que o saber estatístico, enquanto tecnologia de poder e de saber, combina os modos do indivíduo de se conhecer e de se conduzir na sociedade, nas mais diversas situações que surjam em suas vidas, conforme preconiza a legislação.

\section{Considerações}

Começamos a escrita deste artigo buscando o entendimento do saber estatístico como uma tecnologia de governamento e que, como tal, se vincula a práticas a partir de saberes que engendra. Entender o saber estatístico como uma prática de discurso pressupôs compreendermos a articulação existente entre uma sequência de procedimentos, de cálculos e de saberes que permite desenvolver uma série de práticas que objetivam o gerenciamento de condutas.

Nesse pensamento, buscamos, nas produções acadêmicas dos profmatores, as formas 
pelas quais o saber estatístico foi mobilizado nos textos em análise. Mostramos como essas produções se utilizaram dos discursos presentes nos documentos oficiais da Educação para justificar, primeiramente, a escolha da Estatística como objeto de estudo e, posteriormente, os procedimentos metodológicos adotados nas suas pesquisas.

A partir desses entendimentos, mostramos a recorrência dos usos do saber estatístico, pontuados nos textos, como "formas de ler o mundo" e "tomar decisões". Como forma de ler o mundo esse saber se evidencia à medida que produz um tipo de inteligibilidade, fazendo com que se aposte na Estatística como uma ferramenta de leitura do mundo. Essa ciência remete para si um processo de (trans)formação que perpassou o domínio científico para o domínio escolar.

Em relação ao uso do saber estatístico como ferramenta para a tomada de decisão, os profmatores pontuam que esse saber responde às demandas das sociedades contemporâneas que têm a necessidade, entre outras, de compreender informações de cunho estatístico. Conforme a legislação, essas informações podem ser utilizadas "tanto para tirar conclusões e fazer argumentações, quanto para o cidadão agir como consumidor prudente ou tomar decisões em sua vida pessoal e profissional" (BRASIL, 2000, p. 40).

Pensar nas formas como o saber estatístico foi mobilizado nas produções que tratam dos usos do saber estatístico como forma de veridicção desse saber, postas em ação pelo discurso da qualificação docente, nos permitiu pensar em como o saber estatístico possibilitou/possibilita/possibilitará assujeitamentos e subjetivações.

Diante do exposto, a noção do saber estatístico como tecnologia de governamento foi produtiva para percebermos que seus usos operam ora produzindo, ora reproduzindo saberes que posicionam os sujeitos quando da sua relação com números, índices, taxas, gráficos e tabelas, o que produz efeitos nos modos de pensar e de agir dos docentes de Matemática.

É Foucault que nos possibilita compreender como, nas sociedades contemporâneas, caracterizadas como neoliberais, uma tecnologia de governamento serve para gerenciar e potencializar a vida de uma população, fazendo com que as estratégias utilizadas para tanto entrem "no domínio dos cálculos explícitos [fazendo] do poder-saber um agente de transformação da vida humana" (FOUCAULT, 2011, p. 155, grifo nosso).

\section{Referências}

BATISTA, P. R. Modelagem Matemática: uma proposta para o ensino de Estatística. 2013. 103f. Dissertação (Mestrado em Ciências Exatas e da Terra) - Universidade Estadual de Ponta Grossa, Ponta Grossa, 2013. 
BELLO, S. E. L. Jogos de linguagem, práticas discursivas e produção de verdade: contribuições para a educação (matemática) contemporânea. Zetetiké, Unicamp, São Paulo, v. 18, Número Temático, p. 545-588, 2010.

BODART, R. O. Atitudes, concepções e práticas de professores das séries iniciais do ensino fundamental sobre o ensino de Estatística. 2013. 100f. Dissertação (Mestrado em Ciências Exatas e da Terra) - Universidade Federal do Triângulo Mineiro, Uberaba, 2013.

BRASIL. Relatório de Gestão da Diretoria de Formação de Professores da Educação Básica (DEB/2009-2012). Coordenação de Aperfeiçoamento de Pessoal de Nível Superior (CAPES). Brasília, 2013.

BRASIL. Portaria Normativa $\mathrm{N}^{\mathrm{o}} 17$, de 28 de dezembro de 2009. Dispõe sobre o mestrado profissional no âmbito da Fundação Coordenação de Aperfeiçoamento de Pessoal de Nível Superior - CAPES.

Diário Oficial [da República Federativa do Brasil], Brasília, DF, 29 dez. 2009. Seção I, p. 20.

Disponível em:

https://www.capes.gov.br/images/stories/download/legislacao/PortariaNormativa_17MP.pdf $>$. Acesso em: 22 nov. 2011

BRASIL. Ministério da Educação. Secretaria de Educação Fundamental. Parâmetros Curriculares Nacionais de Ensino Médio. Brasília, 2006.

BRASIL. Ministério da Educação. Secretaria de Educação Média e Tecnológica. Parâmetros Curriculares Nacionais (Ensino Médio). Parte IV. Brasília, 2000.

BRASIL. Ministério da Educação/MEC. Secretaria de Ensino Fundamental. Parâmetros Curriculares para o Ensino Fundamental. Brasília, 1997.

CASTRO, F. C. de; CAZORLA, I. M. As armadilhas estatísticas e a formação do professor. In: CONGRESSO DE LEITURA DO BRASIL, 16., 2007, Campinas, SP. Anais... Campinas: ALB, 2007, p. 1-10.

COSTA, E. Proposta de aplicação da Estatística na educação básica: uma investigação do cotidiano com o auxílio do Geogebra. 2013. 66f. Dissertação (Mestrado em Ciências Exatas e da Terra) - Universidade Federal da Bahia, Salvador, 2013.

CURI, L. R. Entrevista concedida pelo presidente do Inep [2016]. Brasília: Luiz Roberto Curi toma posse como novo presidente do Inep. Entrevista Concedida a Assessoria de Comunicação Social do Inep. Disponível em: <http://portal.inep.gov.br/web/guest/conheca-o-inep>. Acesso em: 29 out. 2016.

FISCHER, R. M. B. Foucault revoluciona a pesquisa em educação? Perspectiva, Florianópolis, v. 21, n. 2, p. 371-389, jul./dez. 2003.

FOUCAULT, M. História da Sexualidade I: a vontade de saber. Tradução de Maria Thereza da Costa Albuquerque e Jose Augusto Guilhon Albuquerque. 21. ed. Rio de Janeiro: Edições Graal, 2011.

FOUCAULT, M. Do governo dos vivos: Curso no Collège de France, 1979-1980: excertos. 2. ed. São Paulo: Centro de Cultura Social; Rio de Janeiro: Achiamé, 2011a.

FOUCAULT, M. Em Defesa da Sociedade: curso no Collège de France (1975- 1976). Tradução de Maria Ermantina Galvão. 2. ed. São Paulo: Martins Fontes, 2010.

FOUCAULT, M. Segurança, território, população: curso dado no Collège de France (1977-1978). 1. ed. São Paulo: Martins Fontes, 2008. 
FOUCAULT, M. Diálogo sobre o poder. In: Ditos e Escritos IV: Estratégia, poder-saber. Tradução de Vera Lucia Vellar Ribeiro. 2. ed. Rio de Janeiro: Forense Universitária, 2006. p. 253-266.

FOUCAULT, M. A Ordem do Discurso: aula inaugural no Collège de France, pronunciada em 2 de dezembro de 1970. 11. ed. Campinas: Loyola, 2004.

FOUCAULT, Michel. A Arqueologia do Saber. 8. ed. Rio de Janeiro: Forense Universitária, 2012.

FORTES, D. C. Estudo de Estatística no ensino médio: uma proposta de ensino através da análise de dados sociais e ambientais. 2014. 92f. Dissertação (Mestrado em Ciências Exatas e da Terra) Universidade Federal de Santa Maria, Santa Maria, 2014.

FREITAS, C. M. Ensinando Estatística a partir de um campeonato de futebol com o auxílio de planilha eletrônica. 2013. 26f. Dissertação (Mestrado em Ciências Exatas e da Terra) - Universidade Federal do Ceará, Fortaleza, 2013.

GOMES, V. A. A. A Estatística em foco no município de Barão de Cocais. 2013. 85f. Dissertação (Mestrado em Ciências Exatas e da Terra) - Universidade Federal de Viçosa, Minas Gerais, 2013.

GIL, N. A dimensão da educação nacional: um estudo sócio histórico das estatísticas oficiais da escola brasileira. São Paulo, 2007. 409 f. Tese (Doutorado em Educação) - Faculdade de Educação da Universidade de São Paulo. São Paulo, 2007.

INSTITUTO NACIONAL DE ESTUDOS E PESQUISAS EDUCACIONAIS ANÍSIO TEIXEIRA (Inep). Programa Internacional de Avaliação de Alunos (Pisa): resultados nacionais. Brasília, 2012.

JÚNIOR, H. R. Educação Estatística no Ensino Básico: uma exigência do mundo do trabalho. Revista Capixaba de Ciência e Tecnologia, Vitória, n. 2, p. 35-37, 2007.

LEITÃO, F. M. P. S. Estatística e realidade no cotidiano dos alunos. 2013. 54f. Dissertação (Mestrado em Ciências Exatas e da Terra) - Universidade Federal Rural do Semiárido, Mossoró, 2013.

LOCKMANN, K. Inclusão Escolar: saberes que operam para governar a população. Porto Alegre, 2010. 180f. Dissertação (Mestrado em Educação) - Universidade Federal do Rio Grande do Sul. Porto Alegre, 2010.

LOPES, C. A. E. O ensino da Estatística e da Probabilidade na educação básica e a formação dos professores. Cadernos CEDES, Campinas, v. 28, p. 57-73, 2008.

LOPES, C. A. E. Pensamento Estatístico e Raciocínio sobre variação: um estudo com professores de Matemática. 2003. 281 f. Tese (Doutorado em Educação) - Universidade Estadual de Campinas. Campinas, 2003.

LOPES, C. A. E. A probabilidade e a estatística no ensino fundamental: uma análise curricular. 1998. 125f. Dissertação (Mestrado em Educação) - Universidade Estadual de Campinas. Campinas, 1998.

MESTRADO PROFISSIONAL EM MATEMÁTICA EM REDE NACIONAL (PROFMAT). Disponível em: <http://www.profmatsbm.org.br/funcionamento/regimento/>. Acesso em: Acesso em: 22 nov. 2015.

MORETTI, A. O ensino da Estatística Descritiva a partir da proposta de resolução de problemas. 2013. 33f. Dissertação (Mestrado em Ciências Exatas e da Terra) - Universidade Estadual de Mato Grosso do Sul, Dourados, 2013. 
NASCIMENTO, J. R. A Estatística no ensino básico: abordagem no ENEM e uma análise em alguns materiais didáticos. 2014. 74f. Dissertação (Mestrado em Ciências Exatas e da Terra) - Universidade Federal do Ceará, Juazeiro do Norte, 2014.

NORONHA, G. C. Contribuições da engenharia didática para o ensino e aprendizagem de Estatística na educação básica. 2014. 108f. Dissertação (Mestrado em Ciências Exatas e da Terra) Universidade Federal do Oeste do Pará, Santarém, 2014.

NOVANTA, A. F. Ensino de Estatística através de projetos: uma experiência no $9^{\circ}$ ano do ensino fundamental. 2013. 91f. Dissertação (Mestrado em Ciências Exatas e da Terra) - Instituto Nacional de Matemática, Rio de Janeiro, 2013.

OLIVEIRA, A. L. Ensino de Estatística no Ensino Médio: uma aplicação no $3^{\circ}$ ano para os alunos de Coelho Neto/MA. 2014. 84f. Dissertação (Mestrado em Ciências Exatas e da Terra) - Universidade Federal do Piauí, Teresina, 2014.

SANTOS, O. O. Planeta Energia: uma sequência didática para ensino de estatística. 2013. 52f. Dissertação (Mestrado em Ciências Exatas e da Terra) - Universidade Estadual de Santa Cruz, Ilhéus, 2013.

SENRA. N. de C. O saber e o poder das estatísticas: uma história das relações dos estaticistas com os estados nacionais e com as ciências. 1. ed. Rio de Janeiro: IBGE, 2005.

TEIXEIRA, R. H. VEYNE, Paul. Foucault, sa pensée, sa personne. 1. ed. Paris: Albin Michel. Resenhas. 2008.

VEIGA NETO, A. Coisas do governo... In: RAGO, M.; ORLANDI, L. B. L.; VEIGA NETO, A. (Org.). Imagens de Foucault e Deleuze: ressonâncias nietzschianas. Rio de Janeiro: DP\&A. 2002. p. $13-34$

WALLMAN, K. K. Enhancing Statistical Literacy: enriching our society. Journal of the American Statistical Association, Alexandria, USA, v. 88, n. 421, p. 1-8, 1993. 